\title{
EL CINE DE POESÍA DE PIER PAOLO PASOLINI: ENTRE LA RICOTTA E IL VANGELO SECONDO MATTEO
}

\section{The Cinema of Poetry by Pier Paolo Pasolini: between La ricotta and Il Vangelo secondo Matteo}

\author{
Antonio CANDELORO \\ acandeloro@ucam.edu
}

Recibido: 1/03/2021; Aceptado: 19/04/2021; Publicado: 31/12/2021

Ref. Bibl. ANTONIO CANDELORO. EL CINE DE POESÍA DE PIER PAOLO PASOLINI: ENTRE LA RICOTTA E IL VANGELO SECONDO MATTEO. 1616: Anuario de Literatura Comparada, 11 (2021), 181-201

RESUMEN: El objetivo de este artículo es ilustrar algunas escenas emblemáticas de La ricotta (1963) y de Il Vangelo secondo Matteo (1964) de Pier Paolo Pasolini para analizar cómo el escritor y cineasta italiano reescribe en función poética el texto bíblico, teniendo en cuenta tanto la importancia que cobran las imágenes como los demás elementos cinematográficos, como el uso de la pintura, en función de reescritura intertextual del espacio físico en el que se desarrolla la acción, y de la música, en función de comentario sonoro extradiegético de lo que se narra en la pantalla.

Palabras clave: Pier Paolo Pasolini; cine de poesía; religión; pintura; música; intertextualidad.

ABSTRACT: The objective of this article is to illustrate some emblematic scenes from La ricotta (1963) and Il Vangelo secondo Matteo (1964) by Pier Paolo Pasolini in order to analyze how the Italian writer and filmmaker rewrites the biblical text in poetic function. We will take into account both the importance of images as 
other cinematographic elements, such as the use of painting, as an example of intertextual rewriting of the physical space in which the action takes place, and of music, as extradiegetic sound commentary of what is narrated on the screen.

Key words: Pier Paolo Pasolini; cinema of poetry; religion; painting; music; intertextuality.

\section{A MODO DE INTRODUCCIÓN}

Tanto en La ricotta (1963) como en Il Vangelo secondo Matteo (1964) Pier Paolo Pasolini se interroga alrededor de uno de los nudos más fascinantes y problemáticos de su personalidad: su religiosidad y su concepto de la fe católica, a partir de su compromiso marxista o de comunista marxista que lee e interpreta la realidad a él contemporánea a partir de una ideología de izquierdas. Le ceneri di Gramsci (1957) se titula su primera recopilación poética importante y el título es programático: ahí Pasolini exalta a la figura del fundador del Partido Comunista Italiano, como si este fuera un mito fundacional para la toma de consciencia de la lucha contra las injusticias sociales y a favor de un mundo menos cruel hacia los pobres, los marginados, las clases obreras o las más explotadas por el neocapitalismo de los años 50 y 60.

¿Cómo conjugar el marxismo pasoliniano con su férvida admiración hacia la religión católica, en la que se crio y de la que estaba imbuido desde su infancia? El objetivo de este artículo es ilustrar algunas escenas emblemáticas de ambos textos fúlmicos para analizar cómo Pasolini reescribe en función poética el texto bíblico, teniendo en cuenta tanto la importancia que cobran las imágenes como los demás elementos cinematográficos, como el uso de la pintura en función de reescritura transtextual del espacio físico en el que se desarrollan las acciones y de la música en función de comentario sonoro extradiegético de lo que se narra en la pantalla.

\section{LA RICOTTA: UNA PELÍCULA METACINEMATOGRÁFICA}

La ricotta es un mediometraje de poco más de treinta minutos que forma parte de RoGoPaG, un largometraje compuesto por otros tres capítulos rodados, respectivamente, por Roberto Rossellini, Ugo Gregoretti y JeanLuc Godard (no podemos pasar por alto que cada uno se expresa de una forma diferente al representar en la pantalla su propia idea de cine y de arte cinematográfico). 
La ricotta es, ante todo, y a una primera visión, una película sobre cine: la técnica de la mise en abyme funciona como herramienta principal para involucrar al espectador hasta el final catártico y trágico a la vez. Lo primero que podemos observar al ver la película es un grupo de figurantes que bailan en la campiña romana cerca del set de una película religiosa: hay caravanas, luces, herramientas típicas de un rodaje cinematográfico y...una mesa enorme con comida dispuesta como si de una naturaleza muerta se tratara ${ }^{1}$. Está claro que estamos viendo el cine en su mismo hacerse delante de nuestros ojos; vemos la película in progress, mientras se va haciendo, mientras los figurantes se toman un descanso, mientras los demás actores están a la espera de las órdenes perentorias del director quien, por cierto, es interpretado por Orson Welles, uno de los protagonistas más emblemáticos e icónicos dentro de la Historia del Cine.

Un segundo aspecto que hay que tener en cuenta y que se relaciona con lo que acabamos de comentar es que, en un principio, lo que Orson Welles pretende es crear a través de la cámara cinematográfica (que capta el movimiento de las imágenes mismas) una serie de tableaux vivants que, al contrario, en su esencia, se basan en la reproducción física y real de algunos cuadros famosos de la Historia del Arte: como la crítica no ha dejado de subrayar, en La ricotta Pasolini homenajea (aunque de una forma que podría resultar blasfema o perturbadora o incluso desquiciante) a Rosso Fiorentino y a Jacopo da Pontormo: del primero reproduce la Deposizione di Volterra, de 1521, mientras que del segundo reproduce (o imita a través del uso de cuerpos reales) el Trasporto di Cristo o la Deposizione, de 1526-28. Si los cuadros de ambos artistas toscanos encarnan el dolor y el desconcierto de la Virgen y de los apóstoles y de los demás testigos oculares de la muerte de Cristo, los tableaux vivants que intenta reproducir visualmente Orson Welles en su película encarnan la representación a mitad de camino entre la blasfemia y la risa carnavalesca de unos actores que se caen, que no consiguen estarse quietos o que se ríen a carcajadas porque, puntualmente, los que se ocupan de la banda sonora siempre se equivocan de música; y así, en lugar de escuchar a Scarlatti o a Gluck, el espectador escuchará un twist, el mismo motivo musical alegre y de corte popular con el que arranca la película (y la voz del ayudante del director gritará: «blasfemos!» y añadirá: «Sois peores que los que jugaban a los dados a los pies de la cruz!»).

1. El encuadre podría recordar la famosa escena de la reescritura blasfema de La última cena de Leonardo da Vinci en Viridiana de Luis Buñuel, de 1961, esto es, de tan solo dos años anterior a La ricotta. 
Hilo común de estas dos escenas es el intento de fijar para siempre, de inmovilizar a un grupo de actores llamado a reinterpretar y a reencarnar a los personajes que aparecen en los dos cuadros citados de Fiorentino y Pontormo; y aquí nos topamos con un primer dilema de tipo estético y filosófico: ¿qué sentido tiene -para el cine- congelar imágenes, por muy bellas o artísticamente nobles que estas sean?, ¿cómo puede el cine -arte del tiempo, igual que la literatura-combinar el lenguaje de la pintura -arte del espacio-? Ni es posible animar un cuadro, ni tampoco es posible, para el cine, congelar una imagen de forma definitiva: una película hecha de un solo fotograma no sería una película, sería una fotografía ${ }^{2}$.

Está claro que la elección de los dos cuadros no es nada casual: Pasolini elige a Fiorentino y a Pontormo porque, evidentemente, ambos subrayan los efectos devastadores y profundamente humanos que la muerte de Cristo provoca en los que (lo) asisten en este momento tan emblemático (para él, para los testigos y para el nacimiento del concepto de religión cristiana y católica).

Los personajes pintados por Fiorentino evocan, cada uno a su manera particular, el movimiento de quien desfallece o siente que está a punto de desfallecer; los de Pontormo, cuyos rostros parecen mirarnos, expresan el mismo sentimiento de derrota y de desesperación comprimida o frenada. Es evidente que todo este pathos salta por los aires en la recreación bufonesca o blasfema del director que quiere mantenerse fiel a los dos cuadros evocados, pero que, al mismo tiempo, no puede evitar que alguien se equivoque y ponga una música que ridiculiza la muerte de Cristo o la reduce a farsa cómica, con el resto de la troupe que se ríe a carcajadas (resulta perturbador el encuadre en el que el mismo actor que interpreta a Jesús se echa a reír junto con los demás)3.

2. Cfr. Belting 2002, 97: «El tiempo cinematográfico desaparece en la fotografía, que invariablemente puede comprender solamente un lugar, el que transforma luego en una imagen perenne».

3. Sobre la risa en La ricotta cfr. LóPEZ-Agulló PÉREZ-CABALlero 2013. 


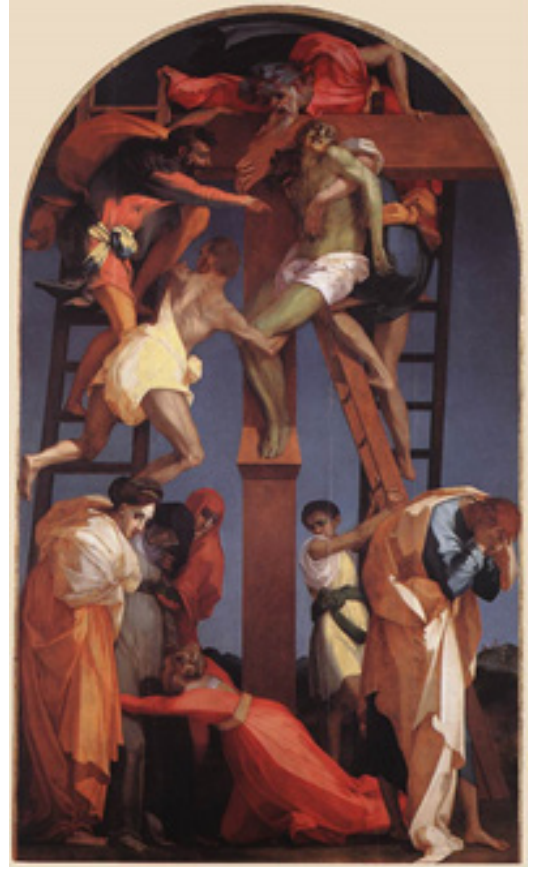

Ilustración 1: Rosso Fiorentino. Deposizione di Volterra (1521).

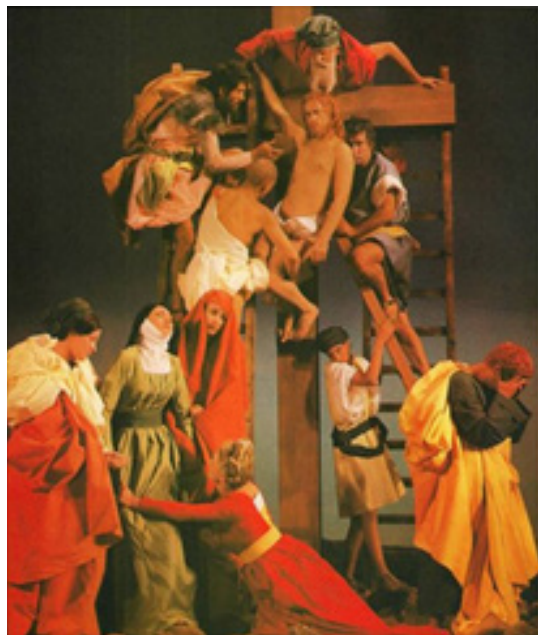

Ilustración 2: Fotograma del primer tableau vivant de La ricotta de Pasolini (1962): Cristo está a punto de caerse. 


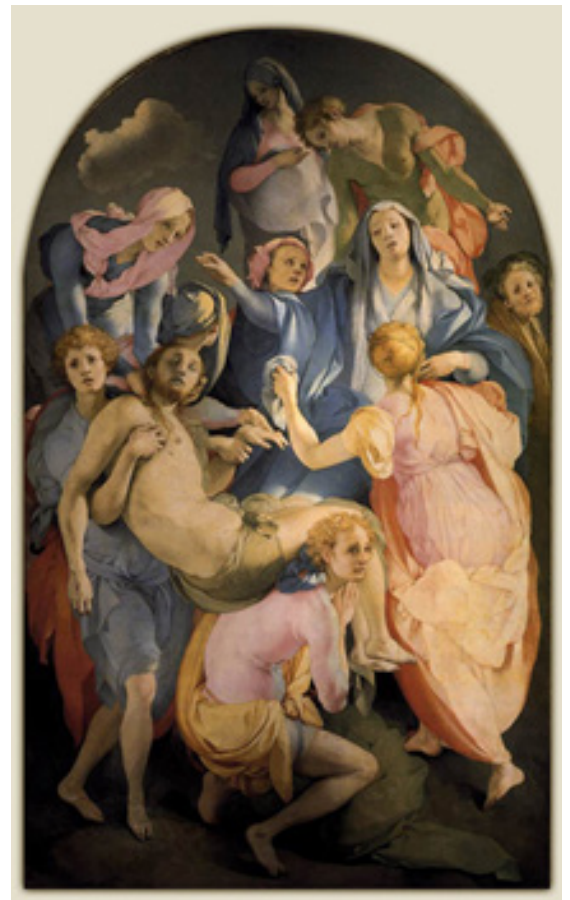

Ilustración 3: Jacopo da Pontormo. Il trasporto di Cristo (o Deposizione) (1526-28).

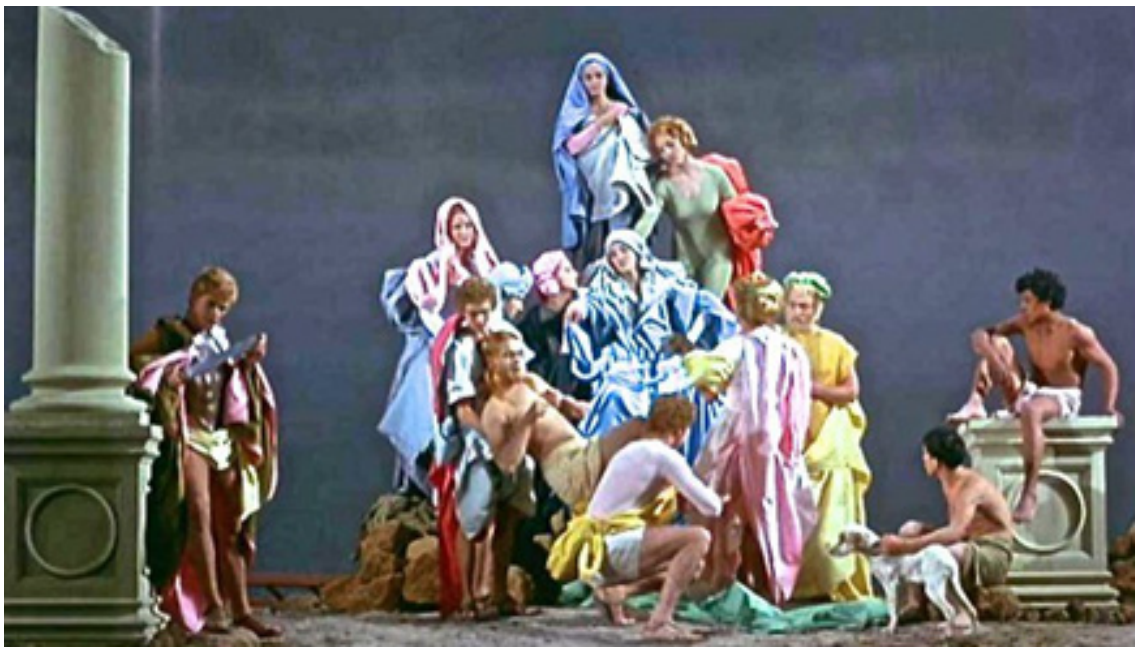

Ilustración 4: Fotograma del segundo tableau vivant de La ricotta de Pasolini (1962): Cristo se cae por segunda vez. 
Es como si Pasolini, lector de Walter Benjamin, nos estuviera mostrando en directo e in fieri la pérdida del aura del arte en la época de su reproductibilidad técnica: las pinturas de Rosso Fiorentino y de Jacopo da Pontormo, tan típicas del arte toscano del siglo XVI, han perdido definitivamente su aura en el siglo $\mathrm{XX}^{4}$. A través del cine y de la cámara fotográfica aquí evocada implícitamente por la técnica de los tableaux vivants puesta en escena por el personaje interpretado por Orson Welles ya es definitivamente posible reproducir las obras de arte fuera de su contexto real, fuera de su entorno espacial y de miles de maneras distintas. Y esto abre interrogantes a los que a día de hoy todavía no sabemos dar una respuesta unívoca: ¿pierden realmente su aura, su significado, las imágenes del patrimonio artístico que heredamos del pasado cuando las reproducimos a través de medios diferentes a su soporte original?, ¿la tecnología actual destruye esa aura o no será acaso capaz de crearles otro tipo de aura?5.

La ricotta, entonces, no se presenta solo como una película sobre el cine, ni tampoco sobre la religión, ni siquiera sobre el arte (o las relaciones que la pintura puede establecer con el cine, esto es, con las imágenes en movimiento). La ricotta es también una película autobiográfica o confesional: a través de Orson Welles y de su máscara, Pasolini nos habla (o le habla al espectador) de sí mismo, de sus cuitas, de sus dudas, de su afán de entender qué es la fe y qué es la religión católica. Y aquí tenemos que subrayar inmediatamente dos elementos: el primero es el encuadre inicial en el que, tras dos citas textuales del Evangelio de San Mateo y del de San Juan, aparece una frase pronunciada con voz en off (fuera del cuadro) por el mismo Pasolini, cuyo timbre es inconfundible para cualquier italiano (incluso para los no cinéfilos). En ese encuadre que funciona, al mismo

4. El famoso ensayo de Benjamin se publicó en 1935, esto es, veintiocho años antes del rodaje de La ricotta. Sobre el concepto de "aura" cfr. Benjamin 2018, 195-223, donde Benjamin la define como «la manifestación irrepetible de una lejanía, por cercana que pueda estar» (201).

5. Intentan contestar a estas preguntas los estudiosos que se interrogan sobre las relaciones entre cine y estética y entre estética y filosofía de las imágenes: entre estos, DIDIHuberman 2006 y 2010; Di Giacomo 2010 y 2016; Montani 2010, además de Montani y CARBONI 2005. Sobre la destrucción del aura y el cambio de percepción que implican el cine y la fotografía con respecto a la pintura cfr. BENJAmin 2018, 217: "Comparemos la tela de la pantalla sobre la que se desarrolla la película con la del lienzo que hace de soporte a una pintura. Esta última invita a la contemplación; ante ella podemos abandonarnos al fluir de nuestras asociaciones de ideas; $y$, en cambio, no podemos hacerlo ante un plano cinematográfico. Apenas lo hemos fijado con los ojos y ya ha cambiado. No es posible fijarlo». ¿Qué diría Benjamin de los espectadores del siglo XXI que ven cine en las pantallas del ordenador o, incluso, en la de los móviles? 
tiempo, como introducción y como paratexto (o umbral, en el sentido que Genette le da al término) del texto fílmico, Pasolini se adelanta a las eventuales críticas de los "puritanos» que podrían equivocarse al limitarse a tildar la película de blasfema y ofensiva contra la religión católica; se trata de un aviso para navegantes y de una indicación de lectura menos partidista o más abierta hacia lo que vamos a ver en la pantalla ${ }^{6}$.

El segundo elemento que hay que tener en cuenta es lo que Orson Welles le dice a un periodista que curiosea entre los figurantes y que se atreve a pedirle una entrevista rápida. En un momento dado, Welles declama algunos versos que aparecerán en la recopilación Poesia in forma di rosa, libro que Pasolini publicará en 1964, esto es, un año después de $L a$ ricotta y el mismo año de Il Vangelo secondo Matteo, y que ya aparecen en el guion de Mamma Roma, publicado por Rizzoli en 1962: de hecho, este es el libro que Orson Welles tiene en las manos (Pasolini 1962, 159-160). Ahora bien: está claro que esa lectura en voz alta de los versos de Pasolini por el personaje del director encarnado por Orson Welles provoca un cortocircuito hermenéutico fundamental para intentar entender la película? Los versos son los siguientes:

Io sono una forza del Passato.

Solo nella tradizione è il mio amore.

Vengo dai ruderi, dalle chiese,

dalle pale d'altare, dai borghi

abbandonati sugli Appennini o le Prealpi,

dove sono vissuti i fratelli.

Giro per la Tuscolana come un pazzo,

per l'Appia come un cane senza padrone.

O guardo i crepuscoli, le mattine

6. Aunque en un segundo momento se vio obligado a cambiar esa introducción leída por él mismo. Cfr. BetTi y GulinuCCi 1991, 63-69 o, en su defecto, González GarCía 1997, $71-72$, nota 6 .

7. En otra ocasión podríamos analizar cómo Pasolini cita algunos fragmentos de $L a$ ricotta y otros de su versión del Evangelio dentro de Poesia in forma di rosa: hay poemas elaborados con técnicas muy cinematográficas; los movimientos de cámara, los objetivos a utilizar para enfocar la escena, la fotografía, el mismo nombre del director de la fotografía (Tonino Delli Colli), los términos del mismo lenguaje cinematográfico aparecen dentro de los versos de algunos poemas donde se habla del rodaje -a mitad de camino entre la confesión, la reflexión metaliteraria y la poesía visual- de tal forma que se podría llegar a hablar de escritura cinematográfica aunque dentro de un género decididamente lírico. Sobre las relaciones entre cine y literatura resultan siempre fundamentales: COSTA 1993; PÉrEz BOWIE 2008, además de PÉrEZ-BOwIe 2010; GIMFERRER 1999. Sobre La ricotta y la problemática intermedial cfr. también GONZÁLEZ GARCía 2017. 
su Roma, sulla Ciociaria, sul mondo, come i primi atti della Dopostoria, cui io assisto, per privilegio d'anagrafe, dall'orlo estremo di qualche età sepolta. Mostruoso è chi è nato dalle viscere di una donna morta. E io, feto adulto, mi aggiro più moderno di ogni moderno a cercare fratelli che non sono più. (Pasolini 2019, 24)

Podríamos intentar traducirlos así:

Yo soy una fuerza del Pasado.

Solo en la tradición está mi amor.

Vengo de las ruinas, de las iglesias, de los retablos de altar, de los pueblos abandonados en los Apeninos y los Prealpes, donde vivieron mis hermanos.

Doy vueltas por la Tuscolana como un loco, por la Appia como un perro sin dueño. O miro los crepúsculos, las mañanas sobre Roma, sobre la Ciociaria, sobre el mundo, como los primeros actos del Después-de-la-Historia, a los que yo asisto, por privilegio de registro, desde el abismo extremo de alguna edad sepultada. Monstruoso es quien nace de las vísceras de una mujer muerta. $\mathrm{Y}$ yo, feto adulto, voy rondando más moderno que cualquier moderno buscando a los hermanos que ya no están

El hecho de que Pasolini se presente a sí mismo como una "fuerza del pasado» dice mucho de su visión de sí mismo y de su relación con el pasado como poeta, cineasta e intelectual. Para Pasolini el pasado no encarna algo

8. La traducción es mía; cfr. también la traducción de Juan Antonio Méndez en PAsoLINI 1982, 28: «Yo soy una fuerza del pasado. / Sólo en la tradición está mi amor. / Vengo desde las ruinas, desde las iglesias, / los retablos de altar, desde los pueblos / abandonados sobre los Apeninos o los Prealpes / donde vivieron mis hermanos. / Doy vueltas por la Tuscolana como un loco, / por la Appia, como un perro sin amo. / O miro los crepúsculos, las mañanas / sobre la Ciociaria, sobre el mundo, / como los primeros actos de la Poshistoria / a los que asisto, por un privilegio de registro civil, / desde el borde de alguna edad / sepultada. Monstruoso es nacer / de una mujer muerta. / Y yo, feto adulto, doy vueltas y revueltas, / más moderno que todos los modernos / buscando hermanos que ya no existen». 
negativo que hay que olvidar o superar de forma rápida a favor del futuro, sino todo lo contrario: en un mundo en el que prevalece la idea del futuro, en el mundo capitalista en el que lo que importa es producir y consumir con la mayor rapidez posible y sin poner demasiadas trabas frente a las desigualdades o a las injusticias que este sistema puede producir y, de hecho, empezó a producir en Italia ya desde el final de la Segunda Guerra Mundial, el pasado encarna un acervo de valores, de ideas, de personajes, de textos que Pasolini no quiere olvidar: porque en la época que él mismo define "Dopo-Storia" (Después-de-la-Historia" -O "Poshistoria", como traduce el neologismo Juan Antonio Méndez en su versión del poema arriba citado-), el pasado puede encarnar una fuerza lúcida que ilumina o podría iluminar el presente frente a un futuro que él interpreta de forma apocalíptica. De ahí la importancia, de nuevo, de las obras pictóricas que Orson Welles se empeña en convertir en cuadros vivientes y, sobre todo, la importancia estructural dentro de la trama de la película de Stracci, el personaje del figurante que está llamado a encarnar al buen ladrón para morir literalmente en la cruz en el momento en el que Orson Welles le pide que actúe frente al productor de la película y a los periodistas y fotógrafos que se han acercado para ver de qué va la obra. Stracci es el muerto de hambre que se desespera y echa a llorar cuando la perrita de una diva cinematográfica que participa en el rodaje se come su bolsa de comida, ganada precisa y religiosamente por su trabajo dentro del set cinematográfico. Stracci es el hombre de la calle que sirve solo para llenar un hueco: el papel del ladrón bueno, al lado del ladrón malo y de Jesús. Stracci (literalmente se puede traducir como andrajos o harapos) es ese pasado que la Italia del boom económico quiere olvidar o quisiera echar fuera del cuadro. En este sentido resultan fundamentales las imágenes aceleradas -casi un ejemplo de slapstick comedy- en las que Stracci echa a correr para comprar el requesón y el pan que consigue adquirir con las mil liras que gana vendiendo la perrita de la diva al periodista mencionado arriba: si un rodaje clásico o estándar se caracteriza por su lentitud y por olvidarse de lo que hacen los figurantes durante la espera, Stracci es el obrero que no puede aguantar todo el día, precisamente por su hambre irrefrenable, causada por una pobreza de la que el director de la película nada sabe o sospecha; los demás figurantes o los asistentes, en cambio, se aprovechan de la proverbial hambre de Stracci para tomarle el pelo y, hacia el final del mediometraje, reírse de él, como si fuera un freak, un fenómeno de circo para contemplar entre el asco y la risa?

9. Resultan emblemáticos estos versos de la tercera sección de Poesia in forma di rosa: «Il Santo è Stracci. La faccia di antico camuso / che Giotto vide contro tufi e ruderi 
La poesía que cita Orson Welles es importante también para subrayar otro elemento: evidentemente, la "fuerza del pasado» la encarna también Cristo. Y no será casualidad que, al año siguiente, Pasolini empiece a imaginar su versión de Il Vangelo secondo Matteo: siendo lo más paradójico el hecho de que si por La ricotta Pasolini sufre un juicio por vilipendio alla religione di Stato, en 1964, por esta segunda obra sobre la religión cristiana, ganará el Premio a la Mejor Película de argumento religioso de parte del OCIC (Office Catholique International du Cinéma) ${ }^{10}$. Tampoco es casualidad que la película esté dedicada a la memoria del papa Juan XXIII (muerto en junio de 1963).

Y la pregunta que tendríamos que hacernos es la siguiente: ¿cómo se articula la reflexión de Pasolini sobre la fe católica y la religión cristiana en un texto sacado explícitamente de la Biblia?, ¿qué puntos en común establece este texto cinematográfico con el texto bíblico en relación con La ricotta?

\section{IL VANGELO SECONDO MATTEO: UN CINE DE POESÍA POLISÉMICO}

Volvamos, de nuevo, al principio: tras la dedicatoria a Juan XXIII ("Alla cara, lieta, familiare memoria di Giovanni XXIII»), en una de las primeras escenas de Il Vangelo secondo Matteo, la música de tipo religioso, esa música clásica que en La ricotta aparece asociada a los nombres de Scarlatti y Christoph Willibald Gluck y que algún operador torpe o blasfemo confunde con el twist del íncipit de la película con el consecuente estallido de histeria del ayudante del director, se hace patente a través de un motivo de Bach. ¿Y cómo se presenta la Virgen María, tras el anuncio del arcángel Gabriel? Como la Madonna del Parto (la Virgen del Parto) de Piero della

castrensi, / i fianchi rotondi che Masaccio chiaroscurò / come un panettiere la sacra pagnotta..." (PASOlini 2019, 78-79; así traduce Méndez, en Pasolini 1982, 80: "Stracci es el santo, La cara de chato antiguo / que viera Il Giotto contra la lava y las ruinas castrenses, / los flancos redondeados que Masaccio claroscuró / como un panadero con una sagrada hogaza»). Stracci no solo remitiría a la figura de Cristo, sino también a los personajes pintados por Giotto y Masaccio (de nuevo, el arte medieval y renacentista italiano).

10. Pasolini parece aludir a esta acusación en los versos del 7 de marzo de la tercera sección de Poesia in forma di rosa (titulada Pietro II): "Ecco, sono stato condannato. / Fatto personale, cicuta che dovrò bermi da solo" (PASOlini 2019, 84); así traduce Méndez, en PASOLINI 1982, 85: "Ya está. He sido condenado. / Acontecimiento personal, cicuta que he de apurar yo solo». La cicuta remite, evidentemente, a la muerte emblemática y altamente simbólica de Sócrates. 
192

Francesca, obra de alrededor de 1460 (anterior a las dos obras de Fiorentino y Pontormo y que el director ruso Andreij Tarkovskij volverá a citar tanto en Nostalgia, de 1983, como en Sacrificio, de 1986).

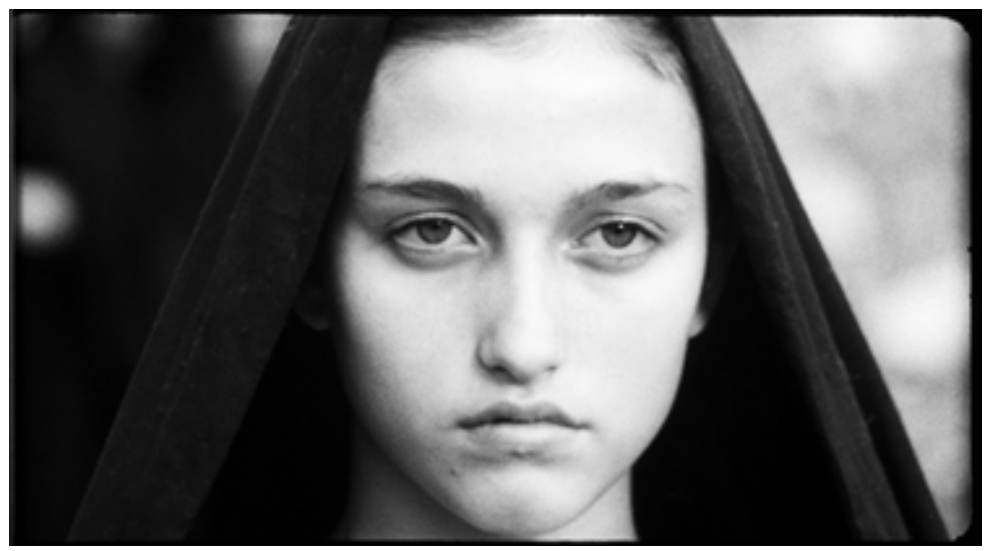

Ilustración 5: La Virgen en Il Vangelo secondo Matteo (1964): primer plano.

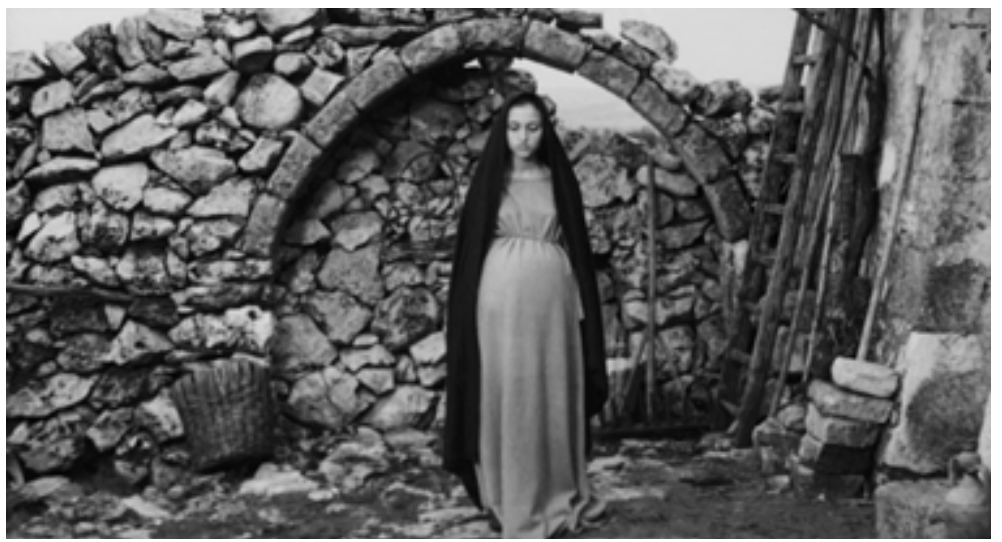

Ilustración 6: La Virgen embarazada en Il Vangelo secondo Matteo (1964). 


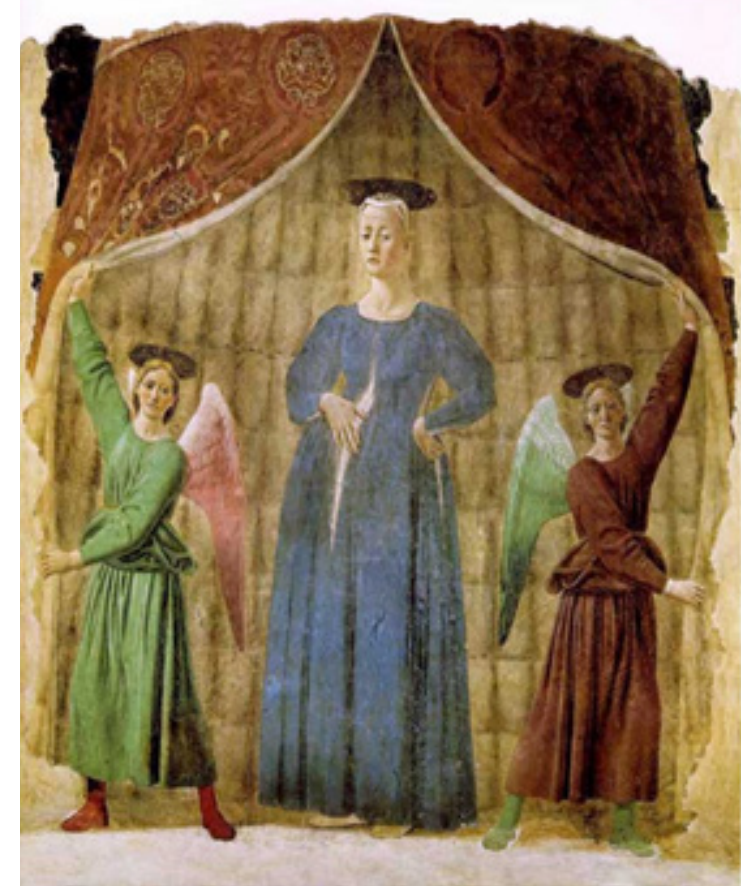

Ilustración 7: Piero della Francesca. Madonna del parto (1460).

He aquí un hilo común: la música clásica y el arte del Renacimiento italiano siguen siendo herramientas útiles para la reconstrucción en el presente del pasado aparentemente lejano de la historia de Cristo tal y como se nos narra en la Biblia ${ }^{11}$.

Si para Pasolini el cine es (o debería ser) «la lengua escrita de la realidad", la Biblia se convierte en $U r$-texto (o supertexto) a través del cual hablar del hombre más allá de las fronteras espaciotemporales, culturales y lingüísticas ${ }^{12}$. Como el mismo escritor y poeta afirma en el artículo «Res

11. No podemos olvidar, a propósito del Renacimiento y del arte italiano, en general, que ya en Mamma Roma (de 1962, esto es, rodada tan solo un año antes de La ricotta) Pasolini cita a Andrea Mantegna en la escena en la que Ettore acaba en la cárcel atado en una mesa: la referencia transtextual e interartística es a la Lamentación sobre Cristo muerto (1475-78) de la Pinacoteca de Brera en Milán (en Il Vangelo secondo Matteo asoma un mismo encuadre atípico en la escena de la muerte de Herodes).

12. Cfr. Pasolini 1991, 198-226. El ensayo se publica en 1966, esto es, dos años después de Il Vangelo secondo Matteo. 
sunt nomina»: "La realtà è linguaggio, e anche nella vita reale, come dialogo pragmatico tra noi e le cose (comprendenti il nostro corpo), mai, nulla è rigidamente monosemico: al contrario quasi tutto è enigmatico perché potenzialmente polisemico» (Pasolini 1991, 260).

El mismo cuerpo de Cristo es un enigma polisémico, al encarnar iconográficamente la que Belting define como una «doble imposibilidad»: la de representar, al mismo tiempo, y simultáneamente, «un cadáver que representa al Dios hecho hombre» $(2002,125)^{13}$.

Y de polisemia podemos hablar también en relación con el uso de la música en la banda sonora de la película: Pasolini juega con la alternancia modulada y sincronizada entre música culta y música popular, entre Mozart y Bach, por un lado, y los cantos africanos o algunos cantos revolucionarios rusos, por el otro ${ }^{14}$.

Pensemos, por citar tan solo un ejemplo, en la escena en la que Cristo cumple el milagro de sanar al cojo: mientras el hombre se acerca lentamente a Cristo, oímos el blues de Blind Willie Johnson Dark was the night, cold was the ground, una canción llena de melancolía y que nos remite a la época de la esclavitud en los estados del Sur de EE. UU. Algunos fariseos le preguntan a Cristo si no es pecado cumplir milagros el sábado; Cristo les contesta con las famosas palabras sobre la oveja descarriada y, refiriéndose al discapacitado, le dice: "Deja tus muletas». En ese momento, de la música del cantante blues pasamos a escuchar un fragmento de Dona Nobis Pacem de la misa en si menor BWV232 de Bach. La emoción que surge de esta escena se debe precisamente al manejo de la música como comentario sonoro extradiegético: en la misma escena, a través de la secuenciación de las imágenes acompañadas, por un lado, por una música blues grabada en el 1927 por un cantante americano que reescribe la escena de la crucifixión de Cristo, y, por el otro, por una pieza de Johann Sebastian Bach de alrededor de 1724 elaborada para el contexto litúrgico de la misa cristiana, Pasolini narra el milagro haciendo estallar las coordenadas espaciotemporales (los EE. UU. de principios del siglo XX, por un lado, y el Sacro Imperio Romano Germánico de principios del siglo XVIII, por el otro) en el arco de los pocos minutos que dura la escena citada. El montaje rompe la linealidad cronológica de las referencias intertextuales precisamente para

13. Tampoco podemos pasar por alto el hecho de que Pasolini -tras haber pensado en Luis Goytisolo y en Yevgueni Yevtushenko- elige como figura destinada a encarnar a Cristo al vasco Enrique Irazoqui, un joven estudiante de izquierdas que visitó Italia (y pudo conocer al director italiano) para recaudar fondos y apoyo político en su lucha antifranquista.

14. Sobre este hipotexto musical cfr. CALABRETTO 1999, 399. 
ampliar de forma atemporal (o heterocrónica) la polisemia del evento que se remonta a los inicios del cristianismo ${ }^{15}$.

Pero también hay poesía en Il Vangelo secondo Matteo en relación con otros elementos fílmicos. Y no me refiero, evidentemente, a la palabra, al texto escrito que Pasolini cita casi verbatim de Mateo (sin quitar ni añadir ni una sola sílaba, como dijo en una entrevista junto con Alfonso Gatto, poeta y amigo que interpreta a uno de los apóstoles), sino a las imágenes y a los encuadres que realiza a lo largo de la película ${ }^{16}$. Por razones de tiempo, citaré solo dos: la primera atañe, de nuevo, a la Virgen: cuando San José se da cuenta de que su mujer está embarazada, se enfada. El juego de las miradas entre los dos es chocante por inquietante. Con dos primeros planos y contraplanos pasamos de la rabia a la alegría de quien sabe que su mujer va a dar a luz a un niño que cambiará la historia de la humanidad. La segunda escena que visualmente se puede interpretar como poesía (y de altísima intensidad, aunque no esté sustentada por ningún tipo de lenguaje verbal, y por depender, al contrario, casi exclusivamente del lenguaje corporal) es la escena de la deposición de Cristo, cuando la Virgen llora desesperada a su hijo. Si en La ricotta esa misma escena se desdobla a través

15. La misma técnica Pasolini la aplica en el milagro del leproso: en este caso el cortocircuito musical (y espaciotemporal) se genera a partir de la secuenciación creativa y la asociación inmediata de, por un lado, el Adagio e Fuga K546 que Mozart compuso en 1788 y, por el otro, el Gloria de la Missa Luba, un canto coral del folklore congolés reelaborado y grabado en 1958 por el franciscano holandés Guido Haazen. Una notación de corte científico y astronómico: en 1977 tanto en el Voyager I como en el II los ingenieros de la NASA colocaron un disco de oro con imágenes y sonidos típicos de la Tierra por si alguna entidad extraterrestre pudiera toparse con sendas sondas espaciales y quisiera entrar en contacto con nosotros. De entre los sonidos se eligieron también motivos musicales famosos de Beethoven, Vivaldi, Bach y Mozart, además de Dark was the night, cold was the ground del citado Willie Johnson. Ambas sondas siguen viajando en el espacio interestelar; Pasolini, obviamente, no podía imaginar que parte de la banda sonora de su Evangelio llegara tan lejos.

16. La entrevista junto con Gatto se puede ver en este enlace: https://youtu.be/o1rqZTt3Z-4 [12 febrero 2021]; sobre las relaciones entre Alfonso Gatto y Pasolini cfr. SPERANZA 2016; sobre la idea de Pasolini de respetar el texto evangélico sin quitar ni una sola sílaba cfr. el puntualísimo estudio de CATALDO 2015, en el que el autor detalla cuáles citas faltan y cuáles milagros eliminó del guion Pasolini (y según qué posibles intenciones estéticas y poéticas). Sobre lo sagrado en el cine de Pasolini cfr. SuBINI 2007, en particular, el último capítulo, pp. 105-118. En Osservazioni sul piano-sequenza (en PASOLINI 1991, 237-241), Pasolini llega a comparar la muerte con el corte final que le dará un nuevo sentido a nuestra vida y al montaje de las escenas más importante de la misma: «Solo grazie alla morte, la nostra vita ci serve ad esprimerci» (241). Son, de nuevo, palabras proféticas, si las relacionamos con la muerte violenta (y a día de hoy todavía llena de misterios) del mismo Pasolini ocurrida el 2 de noviembre de 1975. 
de la cita intermedial de las dos pinturas de Fiorentino y Pontormo, aquí la deposición de Cristo adquiere rasgos poéticos y emotivamente impactantes en el momento en el que el espectador que conoce bien a Pasolini se da cuenta de que la mujer que llora a su hijo es la misma madre del director, Susanna Colussi ${ }^{17}$. Es así como la identificación del «yo» autorial y del «yo» bíblico llega a su máxima tensión y expresión iconográfica ${ }^{18}$ : y es aquí

17. Y en este caso la primera imagen artística que podría surgir en la memoria visual del espectador sería la Piedad (1498-99) de Miguel Ángel, con una diferencia bastante llamativa: si la Virgen que retrata Miguel Ángel en su escultura es joven y dotada de una mirada casi estática, en el caso de la película de Pasolini la Virgen es mayor y llora y grita sin censuras, aunque no la oigamos porque se solapa con la música: en este caso, el aria 39 del Erbarme dich, mein Gott sacada precisamente de la Matthäus-Passion de Bach; Pasolini ya había utilizado esta misma aria en Accattone, de 1961; sobre la importancia simbólica y poética de la música en Pasolini cfr. CAlABretTo 2019. Al Evangelio dedica Pasolini un poema de la VII sección de Poesia in forma di rosa: "Il film l'ho già girato - e con Cristo! / L'ho trovato, Cristo, l'ho rappresentato! / E ora il non trovarlo, il non rappresentarlo / non è che una torbida, ingenua guerra / di sentimenti entrati nella mia anima / da un mondo non mio - che quindi mi aliena” (PASOLInI 2019, 173; así traduce Méndez, en PASOLINI 1982, 192: "Ya he rodado la película - iy con Cristo! / ¡Encontré y representé a Cristo! / Y ahora no encontrarle, no representarle / no es más que una turbia, ingenua guerra / de sentimientos llegados a mi alma / desde un mundo no mío y que por tanto me enajena"). Se trata de versos que bien explicitan la postura unamuniana de alguien que rinde un homenaje a Cristo y a la religión católica desde el punto de vista de su ateísmo ineludible y constante. Los versos también evocan el viaje a Jerusalén que Pasolini realizó en búsqueda de los lugares originales del texto bíblico. La imagen de su madre vuelve en estos versos de Le belle bandiere, también perteneciente a Poesia in forma di rosa: «E mia madre mi è vicina... / ma oltre ogni limite di tempo: / siamo due superstiti in uno. / I suoi sospiri, qua, nella cucina, / i suoi malori a ogni ombra di degradante notizia, a ogni sospetto della ripresa / dell'odio del branco di goliardi che ghignano / sotto la mia stanza di agonizzante / - non sono che la naturalezza della mia solitudine» (108); esta es la traducción de Méndez en PAsolini 1982, 127-128: "Mi madre muy cerca de mí... / pero por encima de todo límite de tiempo: / somos dos sobrevivientes en uno. / Sus suspiros, aquí, en la cocina, / sus desmayos a la menor sombra de noticia degradante, / a la mínima sospecha de un nuevo ataque / del odio de la manada de goliardos que se burlan / al pie de mi habitación de agonizante. / Sólo soy la naturaleza de mi soledad». Pasolini percibe a su madre como "parte» de su soledad y a ambos como "sobrevivientes en uno"; proféticos los versos en los que alude al "odio de la manada", de esos que (la traducción, esta vez, es mía) «rechinan / por debajo de mi habitación".

18. Como nota acertadamente SuBINI 2007, 114: «La sequenza della crocifissione è costruita sovrapponendo al Vangelo di Matteo quello di Giovanni: dal primo provengono le Marie che "stanno a osservare da lontano", dal secondo la presenza della madre. Pasolini viene dunque meno all'aderenza programmaticamente dichiarata al testo di Matteo laddove si insinua il suo vissuto: nella sequenza più autobiografica del film cade ogni remora di fedeltà, perché quel che conta realmente è riattivare il lavoro del cordoglio per cui il film è 
cuando el espectador podrá solapar incluso de forma atemporal el destino del «yo» bíblico con el del «yo» autorial: Pasolini murió de forma violenta por el odio y el desprecio que provocó entre una parte de la sociedad italiana y en un bando político determinado por sus palabras y sus acciones.

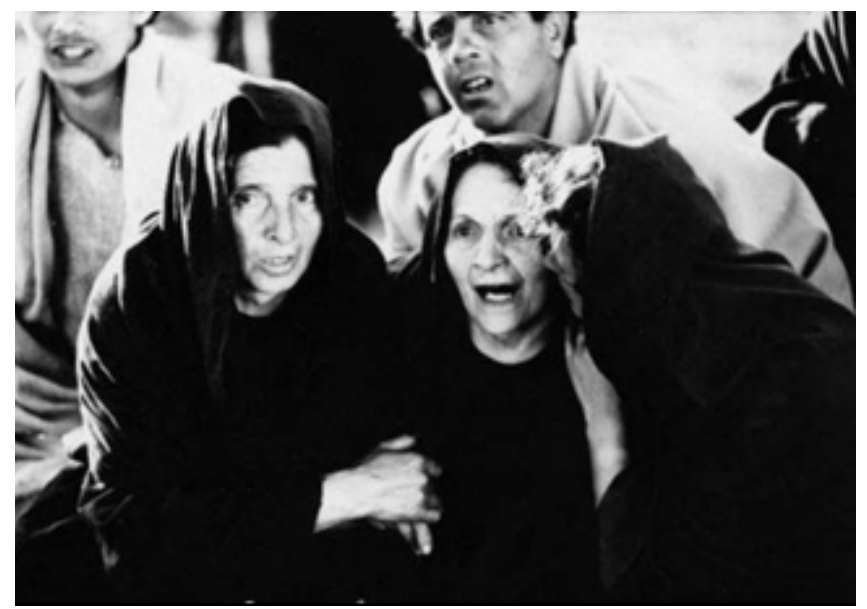

Ilustración 8: Susanna Colussi en el papel de la Virgen en Il Vangelo secondo Matteo (1964).

Quizás estribe en esas secuencias finales de Il Vangelo secondo Matteo la religiosidad más pura de alguien que, inscrito en el Partido Comunista Italiano durante un periodo de su vida y marxista convencido hasta el final de la misma, subrayó de todas las palabras de Cristo la que dice: «No vengo a traer paz, sino espada” (Mt, 10, 34-35). Emblemática es en este sentido la famosa escena del mercado en la que Cristo pone literalmente patas arriba los puestos de los vendedores lanzando su ira verbal contra los fariseos. Y emblemáticos resultan también estos versos del arriba citado Poesia in forma di rosa, casi un diario poético (o poemático) en el que Pasolini convierte en ritmo lírico sus impresiones y sus reflexiones sobre la misma película:

[...] Dove il Cristianesimo

non rinasce, marcisce. E, contraddizione

mille volte, mille volte allusa

dal mio Cristo irriducibile,

stato ideato e realizzato». María aparece debajo de la cruz y al lado del sepulcro solo en el Evangelio de Juan, de hecho, y en ningún otro. Hilo común de los cuatro evangelistas es el hecho de que María nunca habla (y está claro que se trata de un silencio elocuente, sobre todo en relación con la escena de la crucifixión y la de la consecuente resurrección). 
finisce difeso da qualche Erodiano impazzito macabramente privo di senso del ridicolo. (Pasolini 2019, 83)

\section{A MODO DE CONCLUSIÓN}

Lo que en La ricotta es propuesta estética desafiante y heterogénea (con la reflexión paralela sobre la religión, la pintura, el mismo cine como polos privilegiados), en Il Vangelo secondo Matteo se convierte en manifiesto compacto y contundente de una religiosidad que pretende despertar las conciencias de los espectadores a través de un "Cristo irreductible» que lucha contra los Herodes «enloquecidos y macabramente faltos del sentido del ridículo»" "La fuerza del pasado" la encarnan tanto el Stracci de la primera película como el Cristo de la segunda; tanto el espacio primitivo de la periferia romana, como el espacio ancestral de Matera (donde Mel Gibson volverá a rodar The Passion en 2004, con resultados muy diferentes a los de Pasolini $)^{20}$. Y, finalmente, por efecto de ósmosis literaria, esa "fuerza del

19. Sobre este nudo cfr. también el artículo «Marxismo y Cristianismo» en PAsolinI 2018, 116-141.

20. Sobre el problema del espacio en la poética cinematográfica de Pasolini cfr. DeLEUZE 1986, 322: «La imagen visual se torna «arqueológica, estratigráfica, tectónica». No es que se nos remita a la prehistoria (hay una arqueología del presente), sino a las capas desiertas de nuestro tiempo que sepultan a nuestros propios fantasmas, a las capas lacunares que se yuxtaponen según orientaciones y conexiones variables. [...] Son los desiertos de Pasolini, que hacen de la prehistoria el elemento poético abstracto, la "esencia» copresente a nuestra historia, el zócalo arcaico que revela bajo la nuestra una historia interminable». Es en este sentido que podemos hablar de cine de poesía en el caso de Pasolini, más allá de su famoso ensayo Il Cinema di poesia, en PAsolini 1991, 167-187: la poesía surge gracias a la copresencia de elementos visuales, sonoros, gestuales, icónicos que permiten la reconstrucción de esa "prehistoria atemporal" que se percibe también en las demás obras de Pasolini (pensemos en Edipo Rey, de 1967, o en Medea, de 1969, en los que Pasolini recrea el mundo antiguo a partir de la literatura griega, o en Decamerón, de 1971; en Los cuentos de Canterbury, de 1972, y en Las mil y unas noches, de 1974, en los que Pasolini traslada al cine sendos clásicos de la literatura universal; pero esas "capas desiertas" deleuzianas están presentes y vivas también en la fábula satírica de Uccellacci e uccellini de 1966 y en el inquietante y perturbador tratado sobre el mal Saló o los 120 días de Sodoma [1975], quizás la película más indigesta de la historia del cine). Sobre el alcance teórico del citado artículo y los matices que hay que tener en cuenta a la hora de aplicarlo al análisis del cine de Pasolini cfr. Mirizio 2020, además de APRÀ en PASOlini y ROHMER 1970, 5-9. Sobre las relaciones fructíferas entre pasado y presente cfr. PASOLINI 2018, 240-241: «Es ese persistir del pasado en el presente lo que se puede representar objetivamente. Es verdad que el cine (BarthesJakobson) es esencialmente metonímico; sin embargo, en el caso de las películas históricas 
pasado» la encarnará el Orson Welles que, en el caso de La ricotta, lee los que podríamos considerar como algunos de los versos más autobiográficos de un poema de Pasolini ${ }^{21}$.

\section{BiBLIOGRAFÍA}

AprÀ, Adriano. "Premisa». En Pasolini, Pier Paolo y Éric Rohmer. Cine de poesía contra cine de prosa. Barcelona: Anagrama, 1970, pp. 5-9.

Belting, Hans. Antropología de la imagen. Trad. Gonzalo María Vélez Espinosa. Buenos Aires: Katz, 2012 [2002].

Benjamin, Walter. Iluminaciones. Ed. de Jordi Ibáñez Fanés. Trad. Jesús Aguirre y Roberto Blatt. Madrid: Taurus, 2018.

BETTI, Laura y Michele GULINUCCI. Le regole di un'illusione, I film, Il cinema. Roma: Fondo Pier Paolo Pasolini, 1991.

Bogdanovich, Peter. Ciudadano Welles. Conversaciones con Peter Bogdanovich. Madrid: Capitán Swing, 2015.

Calabretto, Roberto. Pasolini e la musica. Pordenone: Cinemazero, 1999.

CALABRETTO, Roberto. «Presenze musicali nelle sceneggiature di Pasolini». En Borin, Fabrizio (ed.). La scrittura per il cinema. Atti dei convegni 2017 e 2018. Trieste: Edizioni Università di Trieste, 2019, pp. 14-37.

Cataldo, Antonio. "Il Vangelo secondo Matteo di Pier Paolo Pasolini (1964). Una religiosità profonda e tormentata». Rudiae. Ricerche sul Mondo Classico, 2015, vol. 1, n. ${ }^{\circ} 25$, pp. 9-31.

Costa, Antonio. Immagine di un'immagine. Milano: Utet, 1993.

Deleuze, Gilles. La imagen-tiempo. Estudios sobre cine 2. Trad. Irene Agoff. Barcelona: Paidós, 1986 [1985].

Didi-Huberman, George. Ante el tiempo. Historia del arte y anacronismo de las imágenes. Trad. Antonio Oviedo. Buenos Aires: Adriana Hidalgo, 2006 [2000].

Didi-Huberman, George. Ante la imagen. Pregunta formulada a los fines de una bistoria del arte. Trad. Françoise Mallier. Murcia: Cendeac, 2010 [1990].

de autor es también -y totalmente- metafórico. El pasado se convierte en una metáfora del presente, en una relación compleja, porque el presente es la integración figural del pasado. ¿Cómo construir esta metáfora? A través de la invención poética y a través de las referencias culturales $[\ldots]$.

21. En el poema del 6 de marzo de la tercera sección de Poesia in forma di rosa, Pasolini define a Orson Welles como "orso gentile come il brontolio di un tuono" (PASOLINI 2019, 82): "Oso amable como el bramido de un trueno», traduce José Antonio Méndez, en PASOLINI 1982, 84. Ese trueno podría recordar el que se oye en la escena de la crucifixión justo después del grito de Cristo y su muerte. El sintagma "Oso amable» coincide con la descripción moral que del director americano nos ofrece alguien que lo conoció de cerca como Peter Bogdanovich: cfr. Bogdanovich 2015. 
Di Giacomo, Giuseppe. Ripensare le immagini. Roma: Mimesis, 2010.

Di Giacomo, Giuseppe. Arte e modernità. Roma: Carocci, 2016.

Giménez Merino, Antonio y Juan-Ramón Josep Torrell y CAPella (eds.). Pier Paolo Pasolini. Todos estamos en peligro. Entrevistas e intervenciones. Madrid: Trotta, 2018.

GIMFERRER, Pere. Cine y literatura. Barcelona: Seix Barral, 1999.

GonZÁlez García, Fernando. El tiempo de lo sagrado en Pasolini. Salamanca: Universidad de Salamanca, 1997.

GONZÁlez GARCíA, Fernando. "Pasolini en Spoleto, 1965. Una performance intermedial». En Pérez-Bowie, José Antonio y Antonio Jesús Gil GonzÁlez (eds.). Ficciones nómadas: procesos de intermedialidad literaria y audiovisual. Madrid: Sial Pigmalión, 2017, pp. 55-79.

López-Agulló PéRez-CABAllero, José Manuel. "La risa en La ricotta de Pasolini». Fotocinema. Revista de Cine y Fotografía, 2013, n. ${ }^{\circ}$ 7, pp. 169-191.

MirizIO, Annalisa. "El cine de poesía: ¿una «referencia literaria innecesaria»?». 1616. Anuario de Literatura Comparada, 2020, n. ${ }^{\circ}$ 10, pp. 35-57.

Montani, Pietro. L'immaginazione intermediale. Roma-Bari: Laterza, 2010.

Montani, Pietro y Massimo CARBOni (eds.). Lo stato dell'arte: l'esperienza estetica nell'era della tecnica. Roma-Bari: Laterza, 2005.

Pasolini, Pier Paolo. Mamma Roma. Milano: Rizzoli, 1962.

PAsolini, Pier Paolo. Poesía en forma de rosa. Trad. Juan Antonio Méndez. Madrid: Visor, 1982.

Pasolini, Pier Paolo. Emperismo eretico. Milano: Garzanti, 1991 [1972].

Pasolini, Pier Paolo. Poesia in forma di rosa. Milano: Garzanti, 2019 [1964].

PÉREZ BowIe, José Antonio. Leer el cine: la teoría literaria en la teoría cinematográfica. Salamanca: Universidad de Salamanca. 2008.

PÉREZ BowIE, José Antonio. Reescrituras fílmicas: nuevos territorios de la adaptación. Salamanca: Universidad de Salamanca, 2010.

Subini, Tomaso. La necessità di morire. Il cinema di Pier Paolo Pasolini e il sacro. Roma: EdS, 2007.

SPERAnZA, Paolo. "Alfonso Gatto, PPP e il cinema». Centro Studi Pier Paolo Pasoli$n i$, 2016. http://www.centrostudipierpaolopasolinicasarsa.it/approfondimenti/ alfonso-gatto-ppp-e-il-cinema-di-paolo-speranza/ [12 febrero 2021].

Filmografía

Buñuel, Luis. Viridiana. México-España, 1961.

GIBSON, Mel. The Passion of the Christ. EE. UU, 2004.

Pasolini, Pier Paolo. Accattone. Italia, 1961.

PASOlini, Pier Paolo. Mamma Roma. Italia, 1962.

PAsolini, Pier Paolo. La ricotta. En RoGoPag. Italia-Francia, 1963.

Pasolini, Pier Paolo. Il Vangelo secondo Matteo, 1964.

Pasolini, Pier Paolo. Uccellacci e uccellini. Italia, 1966.

Pasolini, Pier Paolo. Edipo Re. Italia-Marruecos, 1967. 
Pasolini, Pier Paolo. Medea. Italia-Francia-Alemania, 1969.

PASOlINI, Pier Paolo. Il Decameron. Italia-Francia-Alemania, 1971.

Pasolini, Pier Paolo. I racconti di Canterbury. Italia-Francia, 1972.

Pasolini, Pier Paolo. Il fiore delle Mille e una notte. Italia-Francia, 1974.

PASOlIni, Pier Paolo. Salò o le 120 giornate di Sodoma. Italia-Francia, 1975.

TARKOVSKI, Andreij. Nostalghia. Italia-URSS, 1983.

TARKOvsKI, Andreij. Offret. Suecia-Francia-Reino Unido, 1986. 
